\title{
Timing of Palliative Care Consultation and the Impact on Thirty-Day Readmissions and Inpatient Mortality
}

\author{
John E. Barkley, MD, FCCP, ${ }^{1}$ Andrea McCall, MHA, BSN, RN, CPHQ, ${ }^{2}$ \\ Andréa L. Maslow, PhD, MSPH, ${ }^{3}$ Beata A. Skudlarska, MD, ${ }^{4}$ and Xu Chen, $\mathrm{MSPH}^{5}$
}

\begin{abstract}
Background: Inpatient palliative care consultation (PCC) may reduce 30-day readmissions and inpatient mortality among seriously ill patients.

Objective: To evaluate the impact of timing of PCC on 30-day readmissions and inpatient mortality.

Design: Retrospective, observational study comparing risk-adjusted, observed-to-expected (O/E) 30-day readmissions and inpatient mortality among patients receiving inpatient PCC to all other inpatients.

Setting/Subjects: Adult patients with hospital length of stay (LOS) $<30$ days, primary diagnoses of circulatory, infectious, respiratory, neoplasms, injury/poisoning, and digestive system were included from eight hospitals in a single health care system.

Results: Compared with non-PCC patients $(n=43,463)$, PCC patients $(n=6043)$ had a greater proportion of African Americans, Medicare, LOS $\geq 7$ days, intensive care unit stays, discharges to skilled nursing facility and hospice, primary diagnoses of infections and neoplasms, comorbidities of congestive heart failure, cancer, and dementia, Charlson comorbidity score $\geq 8(p<0.001)$, and fewer males $(p=0.03)$. Adjusted readmission reduction attributed to PCC among 0-2-, 3-6-, and 7-30-day subgroups was $14.1 \%, 19.2 \%$, and $16.4 \%$, respectively (usual care $\mathrm{O} / \mathrm{E}=0.904$ vs. subgroup $\mathrm{O} / \mathrm{Es}=0.764,0.713,0.741$, respectively). Adjusted mortality reductions attributed to PCC among the 0-2- and 3-6-day subgroups were $19.4 \%$ and $19.1 \%$, respectively. A $12 \%$ mortality increase was observed in the 7-30-day subgroup (usual care $\mathrm{O} / \mathrm{E}=0.738$ vs. subgroup $\mathrm{O} / \mathrm{Es}=0.544,0.547,0.858$, respectively).

Conclusions: Inpatient PCC reduces 30-day readmissions and inpatient mortality with the greatest impact demonstrated within six days of hospital admission. Early PCC should be encouraged for eligible patients.
\end{abstract}

Keywords: hospital; mortality; palliative; readmissions

\section{Introduction}

A CUTE CARE HOSPITALS are under increasing pressure by payers to improve clinical and financial outcomes, including 30-day readmissions and inpatient mortality. These measures are now publicly reported and included in the Center for Medicare and Medicaid Services pay-for-performance programs. ${ }^{1-3}$ Seriously ill patients are at greater risk for these unfavorable outcomes.

Palliative care focuses on providing patients relief from pain, other symptoms, and stress of serious illness with the goal to improve quality of life for both patients and families. ${ }^{4}$
Palliative care consultation (PCC) is available in $75 \%$ of hospitals with $>50$ beds and $90 \%$ of those with $>500$ beds. $^{5}$ Multiple studies have documented favorable clinical outcomes with PCC, including improved pain and symptom control, decreased depression and anxiety, and increased satisfaction among both patients and family members. ${ }^{6}$

The impact of PCC on 30-day readmissions and inpatient mortality has been previously reported although no large-scale studies have been published to date. ${ }^{7-12}$ In addition, several of these studies assessed the impact of homebased palliative care or posthospital discharge services on readmissions rather than on inpatient $\mathrm{PCC}$ alone. While

\footnotetext{
${ }^{1}$ Continuing Care Services, ${ }^{2}$ Quality Division, ${ }^{3}$ Information and Analytics Services, ${ }^{4}$ Adult Acute Division, Atrium Health, Charlotte, North Carolina.

${ }^{5}$ Jersey City, New Jersey.

Accepted October 10, 2018.
} 
hospital-based PCC programs were not originally developed to specifically address quality measures such as 30-day readmissions, mortality, hospital length of stay (LOS), or cost of care, these outcomes are increasingly being used to justify the associated cost of these programs.

A significant challenge in conducting palliative care research is the difficulty in performing randomized controlled trials. This is due to a variety of concerns, including physicians' reluctance to allow randomization of their patients and the ethics of withholding a clinical service with a benefit to patient and families that is felt to be well established. ${ }^{13,14} \mathrm{~A}$ variety of risk adjustment methodologies such as case-control matching, propensity score matching, and pre-post comparisons have been utilized to overcome this barrier. ${ }^{15,16}$

Between 2012 and 2014, we conducted several quality improvement analyses on our PCC program. Results suggested a high correlation between the impact of inpatient PCC on 30-day readmissions and inpatient mortality and the timing of the consultation in relation to a patient's admission. Moreover, with the maturation of the program, each analysis demonstrated an increased effect on these outcomes.

The current study examines the impact of PCC on $>6000$ patients across eight hospitals within a large health care system based in the southeastern United States in 2015. The aim of this study was to evaluate the impact of the timing of PCC on 30-day same-hospital readmissions and inpatient mortality. The risk adjustment methodology in this study has been utilized in multiple clinical publications. ${ }^{17-23}$ To our knowledge, it has been utilized only once in studying the impact of palliative care services on risk-adjusted hospital mortality rates. $^{24}$

\section{Methods}

\section{Study population}

Atrium Health comprises 40 hospitals and $>900$ care locations in the southeastern United States with 62,000 employees and 7400 licensed patient beds. With an annual net revenue of $\$ 9$ billion, Atrium Health is one of the largest notfor-profit health care systems in the country. The palliative care program started in a single hospital in 2002. By 2015, the Atrium Health palliative care program provided consultation services in eight acute care hospitals in the Charlotte, North Carolina metropolitan market, which served as the site of this study. The PCC team consisted of 14 physicians, 16 advanced clinical practitioners as well as nurses, social workers, and chaplains.

A retrospective observational study utilized 2015 administrative data to assess the impact of the timing of PCC on 30-day same-hospital readmissions and inpatient mortality. Patients who received a PCC in an acute care setting served as the treatment group with all other acute care patients serving as the comparison (usual care) group. The PCC was delivered by an interdisciplinary team to provide a comprehensive assessment and treatment as clinically indicated. Usual care could have included any nonspecialty-level palliative care interventions. Patients were included if they were older than 18 years, had an LOS of $<30$ days, and primary diagnoses of circulatory, infectious and parasitic, respiratory, neoplasms, injury and poisoning, or digestive system. Excluded were patients with primary diagnoses of rehabilitation, psychiatry, ophthalmology, and obstetrics and patients with Charlson comorbidity scores $<3$. ${ }^{25}$ These criteria were established in an effort to make the comparison groups more homogenous. The study populations were 6043 for the treatment group and 43,463 for the usual care group. Due to specific outcome eligibility requirements, the final study population for the treatment group was 4850 patients for readmissions and 5938 patients for mortality. The final study population for the usual care group was 41,061 patients for readmissions and 42,668 patients for mortality. The study was approved by the Atrium Health Institutional Review Board.

\section{Outcomes}

The primary outcomes of interest were 30-day unplanned, same-hospital readmissions and inpatient mortality. Both raw rates and risk-adjusted outcomes, observed-to-expected $(\mathrm{O} /$ E) ratios, were obtained from Premier's QualityAdvisor ${ }^{\mathrm{TM}}$. Premier is a health care company that collaborates with $\sim 3750$ U.S. hospitals, providing comprehensive outcome data on $\sim 40 \%$ of annual U.S. hospital discharges and $>80$ million discharges to date. ${ }^{26}$ QualityAdvisor is a clinical benchmarking solution that leverages the CareScience ${ }^{\mathrm{TM}}$ risk-adjusted methodology to help hospitals and health systems improve quality outcomes, resource utilization, and eliminate unjustified variation. The observed events were the actual number of readmissions or mortalities, and the expected values were calculated by CareScience risk adjustment methodology based on patient-level, clinical, and facility characteristics. These characteristics include age, sex, race, income, distance traveled, principal diagnosis, CareScience comorbidity scores, cancer status, comorbid conditions and disease history, procedures, point of origin, admission type, payer class, and facility type. CareScience is utilized to evaluate outcomes of care relative to expected outcomes, leveraging an $\mathrm{O} / \mathrm{E}$ ratio, which allows a benchmark comparison across facilities and peer groups. A ratio $\mathrm{O} /$ $\mathrm{E}=1$ indicates the observed outcome was as expected; a ratio $<1$ indicates the outcome was better than expected and $>1$ was worse than expected. This risk adjustment methodology was utilized to create the expected scores allowing for direct comparison of $\mathrm{O} / \mathrm{E}$ ratio outcomes between the treatment group and usual care group.

\section{Statistical analysis}

Descriptive analysis between treatment and usual care groups was performed utilizing chi-squared tests and KruskalWallis tests. All $p$ values were two sided, and all significant results had a $p$ value $<0.05$. Based on prior studies and our own internal data, the impact of PCC may be relative to timing of consultation during hospital stay. ${ }^{27-29}$ Therefore, the treatment group was stratified into three subgroups based on hospital day of consult -0 to 2 days (early), 3 to 6 days (middle), and 7 to 30 days (late) and compared with the usual care group separately.

To avoid overestimating the impact of PCC on readmissions and mortality, we removed the effect of usual care. This was accomplished utilizing $\mathrm{O} / \mathrm{E}$ ratios similar to attributable risk percentage calculations (see Appendix for further detail). 
Table 1. Demographics and Characteristics of Study Population

\begin{tabular}{|c|c|c|c|c|c|c|c|}
\hline \multirow[b]{2}{*}{ Variable } & \multirow{2}{*}{$\begin{array}{c}\text { Usual care } \\
\text { patients } \\
(\mathrm{n}=43,463)\end{array}$} & \multirow{2}{*}{$\begin{array}{c}\text { Palliative care } \\
\text { patients } \\
(\mathrm{n}=6043)\end{array}$} & \multirow[b]{2}{*}{$\mathrm{p}$} & \multicolumn{3}{|c|}{ Palliative care patients by days to consult } & \multirow[b]{2}{*}{$\mathrm{p}$} \\
\hline & & & & $\begin{array}{c}0-2 \text { days } \\
(\mathrm{n}=3300)\end{array}$ & $\begin{array}{c}\text { 3-6 days } \\
(\mathrm{n}=1859)\end{array}$ & $\begin{array}{c}\text { 7-30 days } \\
(\mathrm{n}=884)\end{array}$ & \\
\hline Age, mean (SD) & $67.6(12.5)$ & $70.0(15.8)$ & $<0.0001$ & $70.5(16.4)$ & $70.1(15.5)$ & $68.3(13.8)$ & $<0.0001$ \\
\hline Race, \% & & & $<0.0001$ & & & & \\
\hline Caucasian & 72.1 & 69.0 & & 68.6 & 69.5 & 69.5 & 0.27 \\
\hline African American & 23.9 & 26.4 & & 26.3 & 26.3 & 27.2 & \\
\hline Other & 4.0 & 4.5 & & 5.0 & 4.2 & 3.4 & \\
\hline Gender, male, \% & 48.7 & 47.1 & 0.03 & 45.5 & 48.2 & 51.0 & 0.01 \\
\hline Payer, \% & & & $<0.0001$ & & & & \\
\hline Medicare & 58.1 & 65.5 & & 66.3 & 64.5 & 64.7 & 0.31 \\
\hline Medicaid & 6.4 & 7.8 & & 8.2 & 7.6 & 7.1 & \\
\hline Commercial & 28.9 & 22.2 & & 21.5 & 22.7 & 23.8 & \\
\hline Self-pay & 4.9 & 3.3 & & 2.9 & 4.1 & 3.1 & \\
\hline Others & 1.7 & 1.2 & & 1.2 & 1.1 & 1.4 & \\
\hline \multicolumn{8}{|l|}{ LOS, days, $\%$} \\
\hline $0-2$ & 33.3 & 10.5 & $<0.0001$ & 19.3 & 0.0 & 0.0 & $<0.0001$ \\
\hline $3-\overline{6}$ & 46.5 & 38.9 & & 50.1 & 37.6 & 0.0 & \\
\hline $7-14$ & 17.0 & 36.3 & & 24.8 & 50.7 & 49.0 & \\
\hline $15-30$ & 3.3 & 14.3 & & 5.9 & 11.7 & 51.0 & \\
\hline ICU, \% & 24.3 & 43.7 & $<0.0001$ & 36.4 & 46.1 & 66.1 & $<0.0001$ \\
\hline \multicolumn{8}{|l|}{ Discharge status, $\%$} \\
\hline Home/self-care & 58.0 & 15.9 & $<0.0001$ & 19.1 & 14.6 & 6.9 & $<0.0001$ \\
\hline Home health & 16.8 & 11.2 & & 12.0 & 11.4 & 7.7 & \\
\hline SNF & 13.2 & 24.2 & & 23.1 & 25.9 & 24.9 & \\
\hline Hospice & 1.7 & 23.9 & & 24.0 & 24.1 & 22.9 & \\
\hline Expired in hospital & 3.0 & 17.3 & & 15.6 & 15.7 & 26.7 & \\
\hline Others & 7.3 & 7.5 & & 6.2 & 8.3 & 11.0 & \\
\hline \multicolumn{8}{|l|}{ Primary diagnosis, \% } \\
\hline $\begin{array}{l}\text { Disease of the } \\
\text { circulatory system }\end{array}$ & 33.6 & 18.8 & $<0.0001$ & 19.4 & 19.4 & 15.5 & $<0.0001$ \\
\hline $\begin{array}{l}\text { Disease of the digestive } \\
\text { system }\end{array}$ & 16.3 & 7.8 & & 7.2 & 7.6 & 10.6 & \\
\hline $\begin{array}{l}\text { Disease of the } \\
\text { respiratory system }\end{array}$ & 16.5 & 16.3 & & 16.5 & 16.2 & 15.5 & \\
\hline $\begin{array}{l}\text { Infectious and parasitic } \\
\text { diseases }\end{array}$ & 9.7 & 18.5 & & 17.7 & 18.4 & 22.0 & \\
\hline Injury and poisoning & 15.0 & 8.6 & & 7.6 & 10.1 & 9.5 & \\
\hline Neoplasms & 8.9 & 11.3 & & 11.1 & 12.0 & 10.6 & \\
\hline Others & 0.0 & 18.6 & & 20.5 & 16.3 & 16.3 & \\
\hline \multicolumn{8}{|l|}{ Comorbidities, $\%$} \\
\hline COPD & 5.0 & 3.0 & $<0.0001$ & 3.2 & 2.7 & 2.7 & 0.60 \\
\hline $\mathrm{CHF}$ & 25.7 & 35.5 & $<0.0001$ & 34.0 & 36.9 & 37.9 & 0.03 \\
\hline Cancer & 17.4 & 32.5 & $<0.0001$ & 34.7 & 31.0 & 27.4 & $<0.0001$ \\
\hline End-stage liver disease & 6.0 & 9.1 & $<0.0001$ & 7.9 & 9.4 & 12.8 & $<0.0001$ \\
\hline Dementia & 6.6 & 17.1 & $<0.0001$ & 19.2 & 16.0 & 11.7 & $<0.0001$ \\
\hline Depression & 13.3 & 15.1 & $<0.0001$ & 15.3 & 15.4 & 13.8 & 0.50 \\
\hline \multicolumn{8}{|c|}{ Charlson comorbidity index score, $\%$} \\
\hline $0-2$ & 0.0 & 1.7 & $<0.0001$ & 1.6 & 1.7 & 1.9 & 0.83 \\
\hline $3-\overline{7}$ & 57.9 & 27.1 & & 27.2 & 26.8 & 27.4 & \\
\hline $8-12$ & 36.0 & 54.5 & & 54.2 & 55.7 & 53.2 & \\
\hline $13-22$ & 6.1 & 16.7 & & 17.0 & 15.8 & 17.5 & \\
\hline \multicolumn{8}{|l|}{ Outcomes } \\
\hline Readmissions, O/E & 0.9 & 0.8 & & 0.8 & 0.7 & 0.7 & \\
\hline Observed & 4675.0 & 651.0 & & 372.0 & 193.0 & 86.0 & \\
\hline Expected & 5167.7 & 873.8 & & 487.2 & 270.6 & 116.0 & \\
\hline Inpatient mortality, $\mathrm{O} / \mathrm{E}$ & 0.7 & 0.6 & & 0.5 & 0.6 & 0.9 & \\
\hline Observed & 1291.0 & 1039.0 & & 513.0 & 290.0 & 236.0 & \\
\hline Expected & 1749.3 & 1748.1 & & 942.8 & 530.2 & 275.1 & \\
\hline
\end{tabular}

$\mathrm{CHF}$, congestive heart failure; COPD, chronic obstructive pulmonary disease; ICU, intensive care unit; LOS, length of stay; O/E, observed-to-expected; SD, standard deviation; SNF, skilled nursing facility. 


\section{Results}

A total of 6043 adult admissions representing 5315 unique patients received a PCC across eight acute care hospitals in 2015. A comparison of descriptive characteristics between PCC patients and usual care patients is displayed in Table 1 along with differences between PCC patients by day of consultation. Compared with non-PCC patients, the PCC patients included a greater proportion of African American patients, Medicare, hospital LOS $\geq 7$ days, intensive care unit stays, discharge to skilled nursing facility, discharge to hospice, primary diagnoses of infectious/parasitic diseases and neoplasms, comorbidities of congestive heart failure (CHF), cancer, and dementia, a Charlson comorbidity score $\geq 8$, and a lower proportion of males.

Compared with early PCC patients, late PCC patients had a greater proportion of hospital LOS $\geq 15$ days, primary diagnoses of digestive and infectious/parasitic diseases, and comorbidities of CHF and end-stage liver disease, and a lower proportion of discharges to home with and without home health.

\section{Overall results}

The 30-day same-hospital readmission O/E ratio among 4850 eligible patients who received a PCC was $17.7 \%$ lower compared with the usual care group (0.745 vs. 0.905$)$. After removing the impact of usual care from the impact of PCC, a $16.0 \%(n=140)$ readmission reduction was attributable to PCC. The inpatient mortality O/E ratio among 5938 patients who received a PCC was $19.5 \%$ lower compared with the usual care group (0.594 vs. 0.738). After removing the impact of usual care from the impact of PCC, a $14.4 \% \quad(n=251)$ mortality reduction was attributable to PCC.

\section{Early consults}

The 30-day readmission O/E ratio among 2706 eligible patients who received a PCC on hospital days 0-2 was $15.6 \%$ lower compared with the usual care group (0.764 vs. 0.905). After removing the impact of usual care from the impact of PCC, a $14.1 \%(n=69)$ readmission reduction was attributable

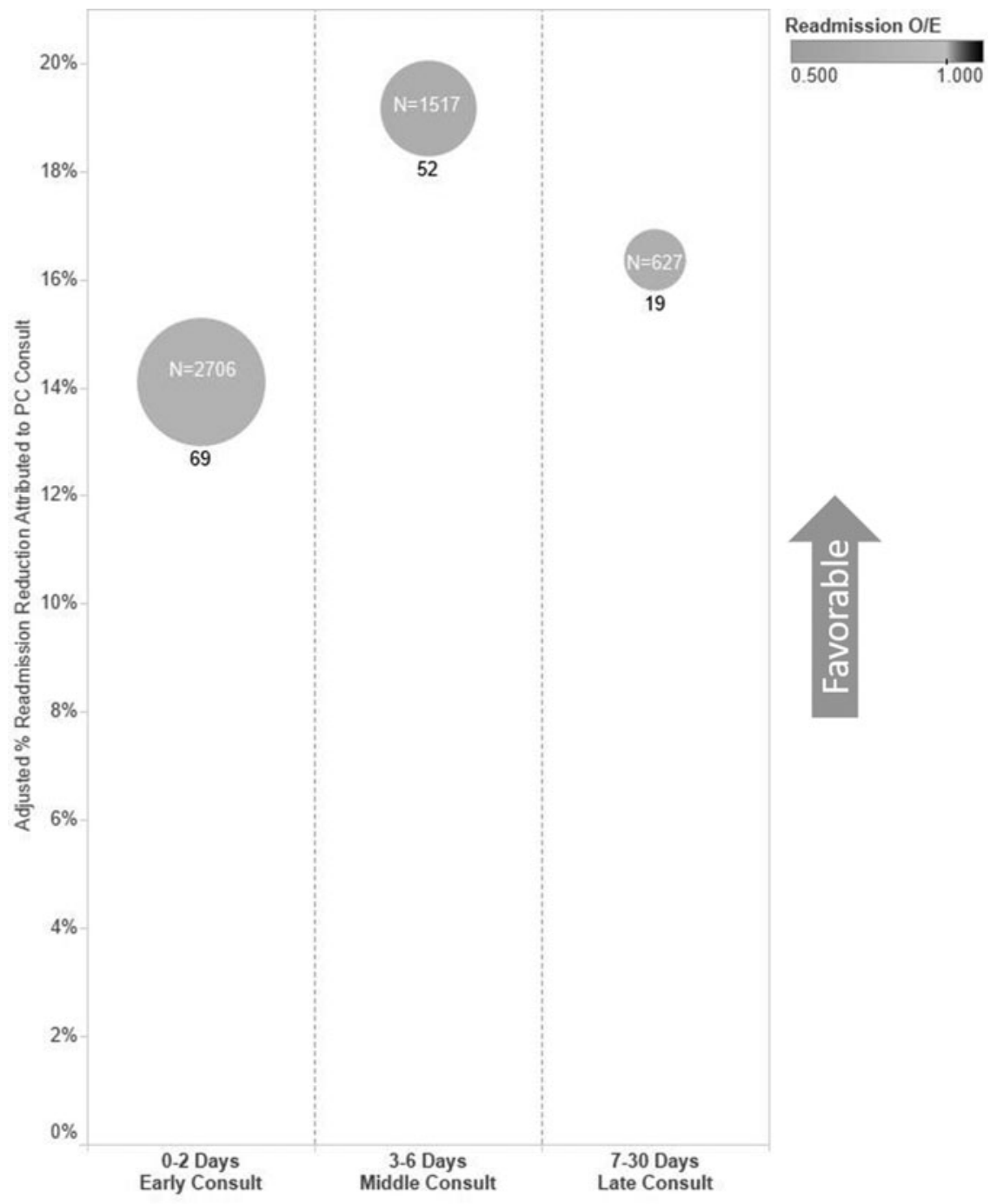

FIG. 1. Adjusted percent of readmission reduction by day of palliative care consult. The size of the circle shows the number of eligible Palliative Care consulted patients in the group. The number directly below the circle represents the number of avoided readmissions. Readmission $\mathrm{O} / \mathrm{E}$ of the usual care group is 0.905 . Light gray color indicates that the readmission $\mathrm{O} / \mathrm{E}$ of the consulted group is lower than 0.905 , and darker color indicates the readmission $\mathrm{O} / \mathrm{E}$ of the consulted group is higher than 0.905. 
to PCC (Fig. 1). The inpatient mortality O/E ratio among 3248 patients who received a PCC on hospital days $0-2$ was $26.3 \%$ lower compared with the usual care group (0.544 vs. 0.738). After removing the impact of usual care from the impact of PCC, a $19.4 \%(n=183)$ mortality reduction was attributable to PCC (Fig. 2).

\section{Middle consults}

The 30-day readmission $\mathrm{O} / \mathrm{E}$ ratio among 1517 eligible patients who received a PCC between hospital days 3-6 was $21.2 \%$ lower compared with the usual care group (0.713 vs. 0.905). After removing the impact of usual care from the impact of PCC, a $19.2 \%(n=52)$ readmission reduction was attributable to $\mathrm{PCC}$ (Fig. 1). The inpatient mortality $\mathrm{O} / \mathrm{E}$ ratio among 1823 patients who received a PCC between days 3-6 of admission was $25.9 \%$ lower compared with the usual care group (0.547 vs. 0.738). After removing the impact of usual care from the impact of PCC, a $19.1 \%(n=101)$ mortality reduction was attributable to PCC (Fig. 2).

\section{Late consults}

The 30-day readmission O/E ratio among 627 eligible patients who received a PCC between hospital days 7-30 was $18.1 \%$ lower compared with the usual care group (0.741 vs. 0.905). After removing the impact of usual care from the impact of PCC, a $16.4 \%(n=19)$ readmission reduction was attributable to $\mathrm{PCC}$ (Fig. 1). The inpatient mortality $\mathrm{O} / \mathrm{E}$ ratio of the 867 patients who received a PCC between hospital days $7-30$ of admission was $16.3 \%$ greater compared with the usual care group (0.858 vs. 0.738). After removing the impact

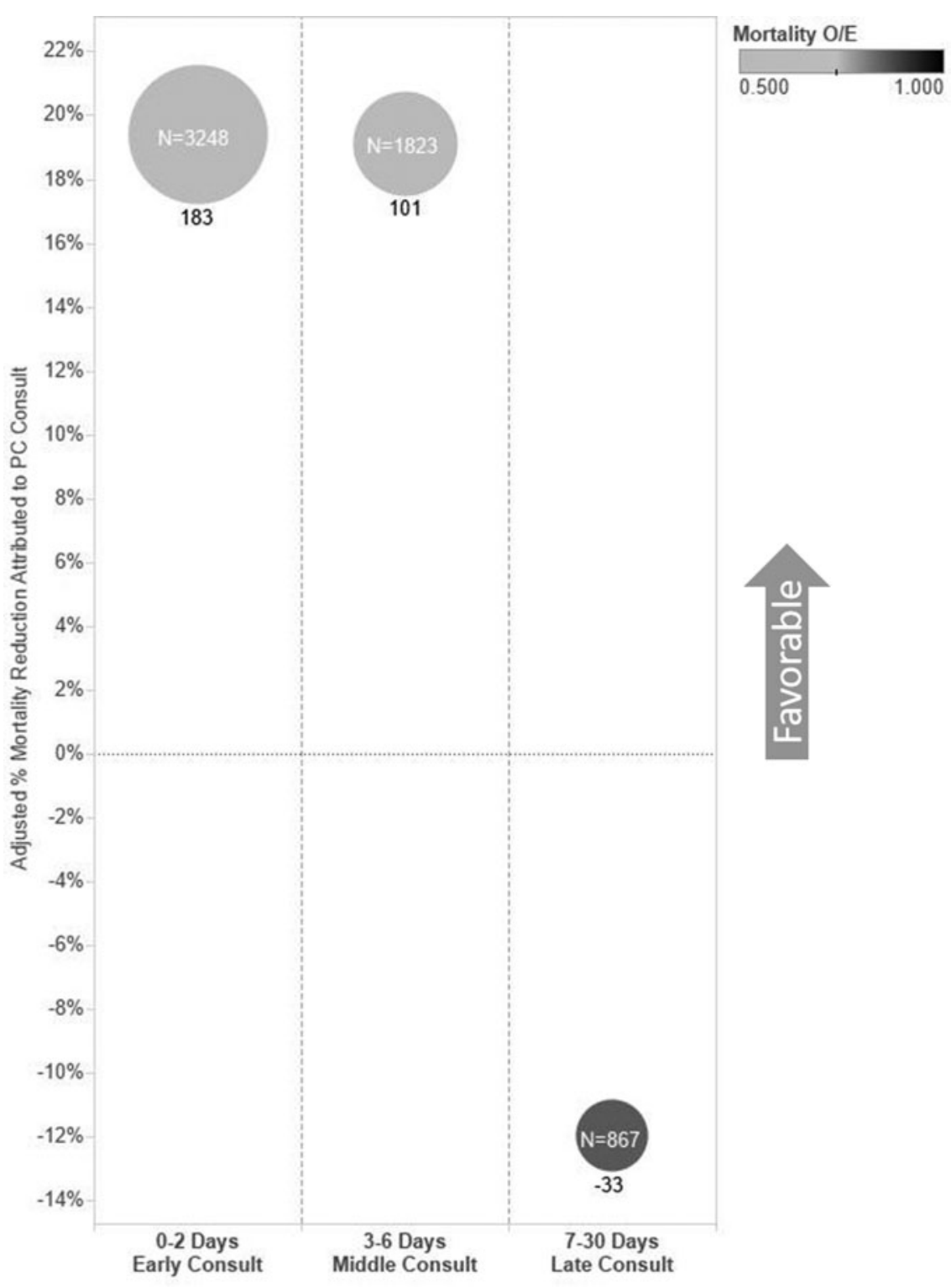

FIG. 2. Adjusted percent of mortality reduction by day of palliative care consult. The size of the circle shows number of eligible Palliative Care consulted patients in the group. The number directly below the circle represents the avoided (excess) number of inpatient deaths. Mortality $\mathrm{O} / \mathrm{E}$ of usual care group is 0.738 . Light gray color indicates that the mortality $\mathrm{O} / \mathrm{E}$ of the consulted group is lower than 0.738 , and darker color indicates the mortality $\mathrm{O} / \mathrm{E}$ of the consulted group is higher than the 0.738 . 
of usual care from the impact of PCC, a $12 \%(n=33)$ mortality increase was attributable to PCC (Fig. 2).

\section{Discussion}

The current study examined the impact of the timing of inpatient PCC on 30-day unplanned, same-hospital readmissions and inpatient mortality. In 2015, PCC was provided to 6043 adult patients across eight hospitals in a single health care system. The eight hospitals range in size from 100 beds in a rural setting to an 875-bed quaternary care academic medical center in an urban setting. We identified significant differences in risk-adjusted 30-day same-hospital unplanned readmissions and inpatient mortality for patients receiving PCC compared with usual care. Analyses assessed the impact of PCC timing on the same outcomes. Patients receiving a PCC within $0-2,3-6$, and 7-30 days of hospital admission were compared with usual care patients. The impact on readmissions remained positive among all timing groups studied, whereas the impact on mortality was positive only in patients consulted within the first 6 days of their hospitalization. Prior researchers have described a reduction in 30-day readmissions and acute care mortality; however, not all focused on hospital-based PCC alone. To our knowledge, this is the largest study to date.

Even though our findings are consistent with prior studies and underscore the need to provide PCC earlier in the hospital stay, this study does not provide a definitive answer as to why the overall impact of palliative care is stronger within the first six days of hospital admission. ${ }^{12,27-29}$ Of note, we found a $12 \%$ increase in mortality for patients consulted during hospital days 7-30. This finding is consistent with at least one prior study. ${ }^{12}$ One possible explanation is that after hospital day 6 , a patient's clinical course is already determined with little ability for PCC to impact mortality. A prospective study design with objective palliative care trigger criteria would be necessary to further evaluate this question.

There are several limitations to our study. First, we did not conduct a randomized controlled trial. Like other authors, we believe that randomization to usual care would be difficult to achieve. Documented challenges include overcoming current physician bias in favor of palliative care as well as ethical concerns regarding withholding a proven clinical intervention. ${ }^{13,14}$ In the absence of a randomized population, we used Premier's CareScience risk adjustment methodology to ensure that the intervention and usual care groups were comparable. The CareScience methodology is well validated and has been utilized in multiple published studies in previous peer-reviewed literature. ${ }^{17-23}$ Furthermore, Atrium Health utilizes CareScience risk adjustment methodology for many quality outcomes; this allows for benchmarking and the ability to account for heterogeneity across our hospitals.

Second, our PCC service does not rely on a standardized trigger tool. This limits our ability to identify the point during hospitalization when patients become eligible for palliative care services. To address LOS differences between the PCC group and the usual care group (mean $\operatorname{LOS}=8.2$ days, 4.6 days, respectively), two additional analyses were performed: (1) PCC patients within each of the three consult timing groups were compared with usual care patients with a minimum LOS equal to or greater than the corresponding PCC subgroup's minimum number of days to consult (e.g., late consults comparison LOS $\geq 7$ days) and (2) The primary analyses were replicated, but with the additional exclusion of all patients with an LOS $>10$ days. The results were consistent-earlier consultations demonstrate a more robust impact on 30-day readmissions and inpatient mortality.

Third, 30-day readmissions were counted only if they occurred in the same hospital. We recognize that claims-based data would provide a more accurate picture of readmissions although the impact of PCC on readmissions in the current study was consistent across all eight hospitals. Fourth, our palliative care program has been in existence for 15 years, making generalization of our findings to newer programs uncertain.

\section{Conclusion}

Our results show that PCC reduces both 30-day readmissions and inpatient mortality and that consultation within the first six hospital days has the greatest impact. Furthermore, palliative care is vital to ensuring the provision of highquality, cost-effective care for patients with serious illness. Intentionally shifting these services "upstream" will require a significant change in our current culture, where the pervasive belief exists that palliative care is only for patients at the end of life.

\section{Acknowledgments}

Special thanks to Leah Lowery, Anja Workman, and Jarrod Bullard for their technical assistance.

\section{Author Disclosure Statement}

No competing financial interests exist.

\section{References}

1. Readmissions Reduction Programs: www.cms.gov/Medicare/ Quality-Initiatives-Patient-Assessment-Instruments/ValueBased-Programs/HRRP/Hospital-Readmission-ReductionProgram.html. (Last accessed September 29, 2018).

2. Hospital Value-Based Purchasing: www.cms.gov/Medicare/ Quality-Initiatives-Patient-Assessment-Instruments/ValueBased-Programs/HVBP/Hospital-Value-Based-Purchasing .html. (Last accessed September 29, 2018).

3. Hospital Compare: www.cms.gov/medicare/quality-initiativespatient-assessment-instruments/hospitalqualityinits/hospital compare.html. (Last accessed September 29, 2018).

4. Morrison RS, Meier DE: Palliative care. N Engl J Med 2004:350:2582-2590.

5. Morrison RS, Meier DE, Dumanovsky T, et al.: America's Care of Serious Illness. 2015 State-by-State Report Card on Access to Palliative Care in our Nation's Hospitals. https:// reportcard.capc.org/wp-content/uploads/2015/08/CAPC-ReportCard-2015.pdf. (Last accessed September 29, 2018).

6. Kelley AS, Morrison RS: Palliative care for the seriously ill. N Engl J Med 2015;373:747-755.

7. Enguidanos S, Vesper E, Lorenz K: 30-Day readmissions among seriously ill older adults. J Palliat Med 2012;15: 1356-1361.

8. Nelson C, Chand P, Sortais J, et al.: Inpatient palliative care consults and the probability of hospital readmission. Perm J 2011;15:48-51.

9. Ranganathan A, Dougherty M, Waite D, et al.: Can palliative home care reduce 30-day readmissions? Results of a 
propensity score match cohort study. J Palliat Med 2013; 16:1290-1293.

10. Cassel JB, Hager MA, Clark RR, et al.: Concentrating hospital-wide deaths in a palliative care unit: The effect on place of death and system-wide mortality. J Palliat Med 2010;13:371-374.

11. Fromme EK, Bascom PB, Smith MD, et al.: Survival, mortality, and location of death for patients seen by a hospital-based palliative care team. J Palliat Med 2006;9: 903-911.

12. Humphreys J, Harman S: Late referral to palliative care consultation service: Length of stay and in-hospital mortality outcomes. J Community Support Oncol 2014;12:129-136.

13. Ewing G, Rogers M, Barclay S, et al.: Recruiting patients into a primary care based study of palliative care: Why is it so difficult? Palliat Med 2004;18:452-459.

14. Carlson MA: Research methods priorities in geriatric palliative medicine. J Palliat Med 2013;16:838-842.

15. May P, Garrido MM, Cassel JB, et al.: Palliative care teams' cost saving effect is larger for cancer patients with higher numbers of comorbidities. Health Aff (Millwood) 2016;35:44-53.

16. Cassel JB, Kerr KM, McClish DK, et al.: Effect of a homebased palliative care program on healthcare use and cost. J Am Geriatr Soc 2016;64:2288-2295.

17. Brailer D, Kroch E, Pauly M: Comorbidity-adjusted complication risk: A new outcome quality measure. Med Care 1996;34:490-505.

18. Pauly MV, Brailer DJ, Kroch EA, et al.: Measuring hospital outcomes from a buyer's perspective. Am J Med Qual 1996; 11):112-122.

19. Kroch EA, Duan M, Silow-Carroll S, et al.: Hospital performance improvement: Trends in quality and efficiencyA quantitative analysis of performance improvement in U.S. hospitals. www.commonwealthfund.org/publications/fundreports/2007/apr/hospital-performance-improvement-trendsin-quality-and-efficiency-a-quantitative-analysis-of-perfor. 2007. (Last accessed September 29, 2018).

20. Kroch EA, Duan M: CareScience risk assessment model: Hospital performance measurement. https://archive.ahrq .gov/professionals/quality-patient-safety/quality-resources/
tools/mortality/KrochRisk.html. 2008. (Last accessed September 29, 2018).

21. Kollef MH, Hamilton CW, Ernst FR: Economic impact of ventilator-associated pneumonia in a large matched cohort. Infect Control Hosp Epidemiol 2012;33:250-256.

22. Bankowitz RA, Doyle B, Duan M, et al.: Identifying hospital-wide harm: A set of ICD-9-CM-coded conditions associated with increased cost, length of stay, and risk of mortality. Am J Med Qual 2014;29: 373-380.

23. Thacker JK, Mountford WK, Ernst FR, et al.: Perioperative fluid utilization variability and association with outcomes: Considerations for enhanced recovery efforts in sample US surgical populations. Ann Surg 2016;263:502-510.

24. Kroch EA, Johnson M, Martin J, et al.: Making hospital mortality measurement more meaningful: Incorporating advance directives and palliative care designations. Am J Med Qual 2010;25:24-33.

25. Charlson ME, Pompei P, Ales KL, et al.: A new method of classifying prognostic comorbidity in longitudinal studies: Development and validation. J Chron Dis 1987;40:373-383.

26. PREMIER: Applied Sciences Solutions. www.premierinc.com/ transforming-healthcare/healthcare-performance-improvement/ premier-applied-sciences. (Last accessed September 29, 2018).

27. Zalenski RJ, Jones SS, Courage C, et al.: Impact of palliative care screening and consultation in the ICU: A multihospital quality improvement project. J Pain Symptom Manage 2017;53:5-12.

28. May P, Garrido MM, Cassel JB, et al.: Prospective cohort study of hospital palliative care teams for inpatients with advanced cancer: Earlier consultation is associated with larger cost-savings effect. J Clin Oncol 2015;33:2745-2752.

29. Bharadwaj P, Helfen KM, Deleon LJ, et al.: Making the case for palliative care at the system level: Outcomes data. J Palliat Med 2016;19:255-258.

Address correspondence to: John E. Barkley, MD, FCCP Atrium Health 4425 Golf Acres Drive, Building $O$ Charlotte, NC 28208

E-mail: john.barkley@atriumhealth.org

ApPEndix

\section{Attributable Avoidance Number Calculation}

When observed-to-expected $(\mathrm{O} / \mathrm{E})$ is $<1, r=\left(1-\frac{O}{E}\right) \times$ $100 \%=\frac{(E-O)}{E} \times 100 \%$ indicates the reduction percentage relative to expected numbers. The difference in the two groups' reduction percentage shows by how much one group reduces more outcomes than another group. Applying the reduction percentage difference on treatment group, the expected number would give the avoided number of outcomes attributable to treatment group.
For example: for 30-day readmission, treatment group has $\mathrm{O} / \mathrm{E} \frac{O_{T}}{E_{T}}=\frac{651}{873.797}=0.745$, usual care group has $\mathrm{O} / \mathrm{E} \frac{O_{U}}{E_{U}}=$ $\frac{4675^{-16}}{5167.676}=0.905$;

Treatment group reduction percentage is $r 1=(1-$ $0.745) \times 100 \%=25.5 \%$, usual care group reduction percentage is $r 2=(1-0.905) \times 100 \%=9.5 \%$;

$r 1-r 2=25.5 \%-9.5 \%=16 \%$ shows that treatment group has $16 \%$ more reduction.

Then the avoidance number of readmission attributable to treatment group is $E_{T} \times 16 \%=873.797 \times 16 \%$. 